\title{
Safety evaluation of Sapindus laurifolius leaf extract in Wistar rats
}

\author{
C. N. Santhosh Kumar, N. B. Shridhar, J. S. Sanganal and Ambika Das ${ }^{1}$ \\ Department of Veterinary Pharmacology and Toxicology, Veterinary College, \\ Karnataka Veterinary, Animal and Fisheries Sciences University, Hebbal, Bangalore- 560024 , Karnataka, India; \\ 1. Department of Kaumarabhrithya, SDM college of Ayurveda and Hospital, Hassan, Karnataka, India. \\ Corresponding author: N. B. Shridhar, Tel: +91-9448059777, Email: sridhar vet@rediffmail.com \\ Received: 13-07-2013, Revised: 27-08-2013, Accepted: 28-08-2013, Publishēd online: 12-10-2013
}

doi: 10.14202 /vetworld.2013.884-888

How to cite this article: Santhosh Kumar CN, Shridhar NB, Sanganal J S and Ambika D (2013) Safety evaluation of Sapindus laurifolius leaf extract in Wistar rats, Veterinary World 6(11): 884-888.

\begin{abstract}
Objectives:The present work was aimed to study the phytochemical composition of the Sapindus laurifolius leaves and toxicological effect of the Sapindus laurifolius leaf extract in a systematic way using Wistar albino rats as a model animal.

Materials and Methods :The identification of phytoconstituents present in the leaf extract was performed using High performance thin layer chromatography (HPTLC). In toxicity studies, the acute oral toxicity study was conducted as per the guidelines of Organization for Economic Co-operation and Development (OECD 423 Acute Toxic Class Method) for testing of chemicals. In repeated dose 28-day oral toxicity study (OECD 407), methanolic leaf extract administered at the dose of 50, 200 and $800 \mathrm{mg} / \mathrm{kg} \mathrm{BW}$ and limit dose of $1000 \mathrm{mg} / \mathrm{kg} \mathrm{BW}$.
\end{abstract}

Results: Saponins, flavanoids, glycosides and bitter principles were the major phytoconstituents identified. In acute toxicity study, the $\mathrm{LD}_{50}$ cut-off values were found to be more than $2 \mathrm{~g} / \mathrm{kg}$ in leaf extract. In repeated dose 28-day oral toxicity, significant $(\mathrm{P}<0.05)$ increase in AST, ALT, BUN and creatinine, significant $(\mathrm{P}<0.05)$ increase in total protein was noticed. The histopathological changes confined to liver, kidney and intestine, revealed mild to moderate hepatotoxicity, severe nephrotoxicity and increased goblet cell activity. The changes were found to correlate with increased dose of leaf extract.

Conclusion:The phytochemical analysis of Sapindus laurifolius revealed the presence of saponins, glycosides, flavonoids and bitter principles. The acute oral toxicity study of $S$. laurifolius methanolic leaf extract in rats resulted in no toxicity even at the highest dose, but in repeated 28-day oral toxicity study revealed mild to moderate hepatotoxicity, severe nephrotoxicity and intestinal damage.

Keywords: hepatotoxicity, nephrotoxicity, phytochemical analysis, Sapindus laurifolius, saponins

\section{I ntroduction}

India has an ancient heritage of traditional medicine. Man and animals mostly depend on vegetable kingdom for their food. Many plants are categorized as poisonous plants. Plants by their metabolic activities besides being the source of feed and fodder, also contain other substances, which are important from medicinal and toxicological point of view.

Plants are commonly used for therapeutic purpose in human beings and animals. However, their toxic feature has not been studied. One such plant Sapindus laurifolius (Indian soap nut) belonging to the family Sapindaceae has antibacterial, exfoliant, expectorant, emetic properties, clears the skin problems like eczema, psoriasis, itchy skin [1,2], and fruits and leaves of $S$. laurifolia are acrid bitter, emetic, astringent, anthelmintic, abortifacient and tonic $[3,4,5]$. Although it has so many medicinal properties $[6,7]$, it was reported that consumption of fruits and leaves of the plant S.laurifolius caused toxicity in cattle. There was severe diarrhoea, which was attributed to the saponin content of the plant leaf.

Copyright: The authors. This article is an open access article licensed under the terms of the Creative Commons Attribution License (http://creativecommons.org/licenses/by/2.0) which permits unrestricted use, distribution and reproduction in any medium, provided the work is properly cited.
During the disease investigation process, it was noticed that the cattle that consumed the fresh leaves of the plant Sapindus laurifolius exhibited the clinical signs viz., excitation, convulsion, diarrhoea and died [8].

Hence the present work was aimed to study the phytochemical composition of the S. laurifolius leaf extract, to conduct acute and sub-acute toxicity study of the S. laurifolius in rats, and to correlate the findings with histopathological and biochemical studies.

\section{Materials and Methods}

Ethical approval: Experimental protocol was approved by Institutional Animal Ethical Committee.

Plant extract: S. laurifolius fresh leaves were collected from Western Ghats of Karnataka State and dried under the shade. The dried powdered material was subjected to repeated extraction by maceration at room temperature with methanol as a solvent. Extract was filtered and concentrated and dried at reduced pressure and controlled temperature $\left(40-60^{\circ} \mathrm{C}\right)$ in a rotary evaporator. The residual methanol from the extract was evaporated after keeping the extracts in a vacuum oven at $60^{\circ} \mathrm{C}$ at the pressure of 25 psi (Murophy, India). The residues were weighed after drying and their respective percentage yield was estimated. The final residual leaf extract was used for phytochemical and toxicological analysis. 
Phytochemical analysis: The phytochemical investigation of $S$. Laurifolius using high performance thin layer chromatography (HPTLC) technique was carried out following the method of Wagner et al [9].

Methanolic extract obtained was evaporated under reduced pressure using rotary evaporator. Extract residue was re-dissolved in $1 \mathrm{ml}$ of chromatographic grade methanol, which was used for sample application. Application of bands of leaf extract was carried out $(4 \mathrm{~mm}$ in length and $5 \mathrm{ul}$ in concentration for leaf) using spray technique. Sample were applied in duplicate on pre-coated silica gel 60F254 aluminium sheets with the help of Linomat 5 applicator attached to CAMAG HPTLC system, which was programmed through WIN CATS software. After the application of sample, the chromatogram was developed in Twin trough glass chamber $10 \mathrm{x} 10 \mathrm{~cm}$ saturated with solvent ethyl acetate: methanol: water (100:17:13) for 15 min.This procedure was followed for the analysis of alkaloids, anthracene derivatives, flavonoids, bitter principles, coumarins, saponins and glycosides.

Experimental design: Healthy Wistar albino rats aged around 8-9 weeks weighing $160 \pm 20 \mathrm{~g}$ were obtained from the stock of the animal house, Indian Institute of Sciences, Bangalore, Karnataka (India) Animals were acclimatized to the laboratory conditions for 7 days prior to the study and maintained on normal diet and $a d$ libitum water.

The animals were fasted overnight prior to the administration of the plant extract. The methanolic leaf extract of $S$. laurifolius in graded doses were administered to animals as a single dose by oral gavage. The volume of administration was maintained to $2 \mathrm{ml} / 200 \mathrm{~g}$ through proper dilution of methanolic leaf extract in distilled water.

Acute toxicity study: Acute toxicity was determined according to the OECD guidelines No.423. Female Wistar rats ( $n=3$ per step) were selected by random sampling technique. The rats were kept fasting for overnight providing with water ad libitum. The methanolic extract of $S$. laurifolius was administered at a dose rate of 5, 50, 300 and $2000 \mathrm{mg} / \mathrm{kg}$ body weight. Food was withheld for further 3-4 hrs and observed once in $30 \mathrm{~min}$ during the first $24 \mathrm{hrs}$ and daily thereafter, for a period of 14 days for any mortality [10].

Repeated dose 28-day oral toxicity study: Repeated dose 28-day oral toxicity was determined according to the OECD guidelines No.407. Wistar rats divided into five groups $(n=6)$ of either sex were used for the study. Group I served as control which was gavaged with distilled water where as group II, III and IV were gavaged with $S$. Laurifolius methanolic leaf extract at the dose level of $50,200,800 \mathrm{mg} / \mathrm{kg}$ daily, respectively for 28 days. Satellite group rats (group V) administered with $800 \mathrm{mg} / \mathrm{kg}$ of leaf extract for 28 days and discontinued until $42^{\text {nd }}$ day to observe any reversibility in toxicity. Limit test at one dose level of at least 1000 $\mathrm{mg} / \mathrm{kg}$ body weight/day was conducted. The rats were weighed individually at the beginning of the study and at weekly interval till day 28. Daily all the rats were observed for the clinical signs of toxicity, morbidity and mortality.

Haematology and clinical biochemistry: The blood samples were obtained by retro-orbital plexus puncture method on day 0,14 and 28 and the fresh blood was used to estimate haematological parameters like Total Erythrocyte Count (TEC), Total Leucocyte Count (TLC), haemoglobin (Hb) and Packed Cell Volume (PCV). In clinical biochemistry, serum was used to estimate serum concentrations of alanine aminotransferase (ALT), aspartate aminotransferase (AST), creatinine (CRT) and blood urea nitrogen (BUN) using biochemical analyzer and commercially available diagnostic kits.

Gross and histopathological studies: Rats were sacrificed humanely at the end of the study. Organs were weighed and representative tissue samples of various organs were collected in $10 \%$ normal buffer formalin solution (NBF) and were subjected to histopathology [11].

Statistical analysis: The data obtained were analyzed on Graph Pad prism 5.01 software and expressed as Mean \pm SEM. The Statistical analysis was performed by using two-way ANOVA, Bonferroni post-test as per the standard procedures [12] to compare the treated and control groups.

\section{Results}

The Phytochemical analysis of $S$. Laurifolius leaf extract was found positive for saponins, glycosides, flavonoids and bitter principles in High performance thin layer chromatography.

Acute oral toxicity study: There were no deaths and no clinical signs of toxicity in any of the test groups within $24 \mathrm{~h}$ after the administration of $S$. laurifolius leaf extract. The treated groups were kept for observation for a period of 14 days. No mortality and no clinical signs of toxicity were observed in any of the tested groups in a given dose and duration.

All the tested groups of animals were sacrificed on day 15. Detailed post mortem examination was carried out and all the experimental animals did not reveal any gross pathological changes. The histological examination of various organs of both male and female rats revealed normal architecture of all the organs.

Repeated dose 28-day oral toxicity study: The determination of oral toxicity using repeated doses was carried out after initial information on toxicity was obtained by acute oral toxicity testing. There were no deaths but animals exhibited clinical signs such as depression, weakness, salivation, diarrhoea and decreased body weight gain in $800 \mathrm{mg} / \mathrm{kg}$ and limit dose group $(1000 \mathrm{mg} / \mathrm{kg})$ rats administered with methanolic leaf extract of $S$. laurifolius.

In the present study, there was a significant increase $(\mathrm{P}<0.01)$ in serum ALT and AST concentrations in the serum samples of 800 and $1000 \mathrm{mg} / \mathrm{kg}$ 
Table-1. Levels of alanine aminotransferase ALT (U/L) in rats fed with S. laurifolius leaf extract in repeated dose 28 day oral toxicity study

\begin{tabular}{llllll}
\hline Day & Group I & Group II & Group III & Group IV & Group V \\
\hline 0 & $27.50 \pm 2.97$ & $26.22 \pm 2.39$ & $27.60 \pm 2.89$ & $27.82 \pm 2.53$ & $26.52 \pm 2.36$ \\
14 & $27.68 \pm 2.76$ & $28.10 \pm 1.76$ & $29.30 \pm 1.73$ & $29.27 \pm 1.89$ & $28.53 \pm 1.24$ \\
28 & $27.35 \pm 2.16$ & $28.80 \pm 1.25$ & $28.65 \pm 1.21$ & $35.30 \pm 1.39^{* *}$ & $35.63 \pm 2.18^{* *}$ \\
42 & $28.88 \pm 2.19$ & - & - & - & $34.52 \pm 1.53^{*}$ \\
\hline
\end{tabular}

Values are Mean $\pm \mathrm{SEM}, * \mathrm{P}<0.05, * * \mathrm{P}<0.01, \mathrm{n}=6$, the values on day 42 pertain to satellite group

Table-2. Levels of aspartate aminotransferase AST (U/L) in rats fed with S. laurifolius leaf extract in repeated dose 28 day oral toxicity study

\begin{tabular}{llllll}
\hline Day & Group I & Group II & Group III & Group IV & Group V \\
\hline 0 & $56.48 \pm 2.17$ & $55.13 \pm 2.47$ & $57.78 \pm 1.53$ & $56.78 \pm 2.27$ & $55.25 \pm 2.13$ \\
14 & $57.67 \pm 1.98$ & $56.97 \pm 2.06$ & $57.33 \pm 2.97$ & $56.83 \pm 1.49$ & $58.48 \pm 1.54$ \\
28 & $56.53 \pm 1.73$ & $57.05 \pm 2.31$ & $56.85 \pm 2.17$ & $64.15 \pm 1.50^{* *}$ & $64.07 \pm 1.66^{\star *}$ \\
42 & $57.32 \pm 1.67$ & - & - & - & $54.13 \pm 1.13$ \\
\hline
\end{tabular}

Values are Mean $\pm \mathrm{SEM}, * * \mathrm{P}<0.01, \mathrm{n}=6$, the values on day 42 pertain to satellite group

Table-3. Levels of blood urea nitrogen BUN ( $\mathrm{mg} / \mathrm{dl}$ ) in rats fed with S. laurifolius leaf extract in repeated dose 28 day oral toxicity study

\begin{tabular}{lllllll}
\hline Day & Group I & Group II & Group III & Group IV & Group V & Limitdose \\
\hline 0 & $18.90 \pm 1.61$ & $20.38 \pm 1.63$ & $21.15 \pm 0.26$ & $19.10 \pm 1.39$ & $17.42 \pm 1.57$ & $19.00 \pm 1.08$ \\
14 & $18.85 \pm 0.95$ & $20.40 \pm 0.66$ & $21.07 \pm 0.52$ & $23.95 \pm 0.83^{\star *}$ & $23.58 \pm 1.02^{\star *}$ & $23.25 \pm 0.68^{*}$ \\
28 & $18.98 \pm 1.66$ & $18.78 \pm 0.94$ & $20.08 \pm 1.23$ & $24.63 \pm 1.27^{* *}$ & $23.98 \pm 1.02^{* *}$ & $27.25 \pm 0.42^{\star * \star}$ \\
42 & $20.40 \pm 0.66$ & - & - & - & $24.62 \pm 0.51^{*}$ & - \\
\hline
\end{tabular}

Values are Mean $\pm \mathrm{SEM}, * \mathrm{P}<0.05, * * \mathrm{P}<0.01, * * * \mathrm{P}<0.001, \mathrm{n}=6$, the values on day 42 pertain to satellite group

Table-4. Levels of serum creatinine $(\mathrm{mg} / \mathrm{dl})$ in rats fed with $\mathrm{S}$. laurifolius leaf extract in repeated dose 28 day oral toxicity study

\begin{tabular}{|c|c|c|c|c|c|c|}
\hline Day & Group I & Group II & Group III & Group IV & Group V & Limit dose \\
\hline 0 & $0.73 \pm 0.02$ & $0.73 \pm 0.02$ & $0.73 \pm 0.03$ & $0.71 \pm 0.03$ & $0.75 \pm 0.03$ & $0.72 \pm 0.02$ \\
\hline 14 & $0.76 \pm 0.03$ & $0.79 \pm 0.03$ & $0.78 \pm 0.02$ & $0.94 \pm 0.04^{*}$ & $0.94 \pm 0.03^{*}$ & $0.98 \pm 0.09^{* *}$ \\
\hline 28 & $0.78 \pm 0.03$ & $0.83 \pm 0.04$ & $0.90 \pm 0.03^{*}$ & $1.14 \pm 0.09^{\star \star *}$ & $1.13 \pm 0.11^{\star \star *}$ & $1.08 \pm 0.08^{\star \star *}$ \\
\hline 42 & $0.77 \pm 0.04$ & - & - & - & $0.95 \pm 0.04^{*}$ & - \\
\hline
\end{tabular}

Values are Mean $\pm \mathrm{SEM}, * \mathrm{P}<0.05, * * \mathrm{P}<0.01, * * * \mathrm{P}<0.001, \mathrm{n}=6$, the values on day 42 pertain to satellite group

treated groups on day 14 and 28 (Table-1, 2) and significant $(\mathrm{P}<0.05)$ increase in the serum total protein level on the day 28. The serum urea nitrogen and serum creatinine concentration in rats increased significantly $(\mathrm{P}<0.001)$ from day 14 to 28 in groups treated with 800 and $1000 \mathrm{mg} / \mathrm{kg}$ of leaf extract (Table-3,4).

There was a significant $(\mathrm{P}<0.05)$ difference between the satellite group and control satellite group ALT, BUN and serum creatinine values at day 42 [Table-1, 3, 4], this indicated the injury to the kidney and liver was continued even after the administration of S. laurifolius leaf extract was stopped. The kidney damage caused by the $S$. laurifolius leaf extract in the present study, might take still longer time to get recovered or it might be irreversible in nature.

There was no significant change in TEC, TLC, $\mathrm{Hb}$ and PCV values in any of the rat groups administered with $S$. laurifolius leaf extract. This implied that $S$. laurifolius do not affects haemopoetic system even at the high dose level.

The rats administered with methanolic leaf extract of S. laurifolius showed varying degree of histopatholigical lesions in liver, kidney and intestine in all the treated groups, where as remaining organs retained their normal architecture. This altered level of AST, ALT, serum creatinine and BUN was further supported by the gross and histopathological lesions in high dose groups, by the presence of swollen hepatocytes vacuolar degeneration, congestion of central veins and liver sinusoids, necrosis of individual hepatocytes, prominent bile duct hyperplasia in liver [Figure-1], kidney showed haemorrhages and distension of tubular and glomerular epithelium, desquamation of tubular epithelium, intertubular and glomerular hemorrhagic areas, vacuolations of the glomerular epithelium, hypercellularity of tubular and inter tubular spaces [Figure-2]. In intestine increased goblet cell activity, broadening of villus structure, focal areas of inflammatory cells infiltration in lamina propria and submucosa, oedema of the submucosa [Figure-3].

\section{Discussion}

The S. Laurifolius leaf extract consist of saponins, glycosides, flavonoids and bitter principles. These phytochemical constituents might be responsible for the biological activity of the $S$. laurifolius leaves. Among the chemical constituents, saponins are most important biologically $[13,14,15]$.

Acute toxicity study gives a clue on the range of doses that could be used in subsequent toxicity testing and estimating the therapeutic index of drugs and xenobiotics. In our study, there were no deaths and clinical signs of toxicity in any of the test groups within 


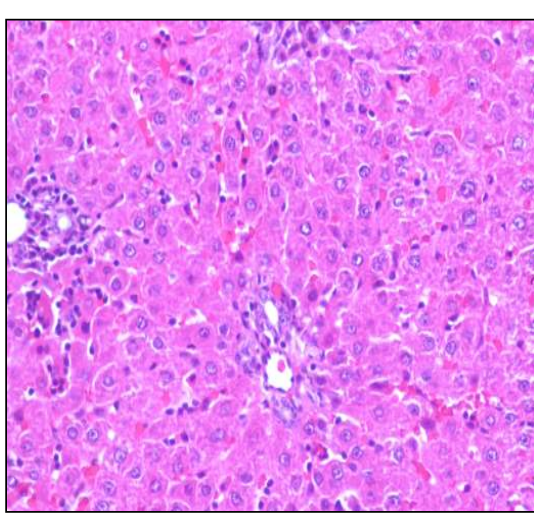

Figure-1. Histopathology image of liver from Group IV rat showing swollen and granular hepatocytes, congestion, prominent biliary hyperplasia in periportal region in repeated 28 day toxicity study by $\mathrm{H}$ and $\mathrm{E}$ stain $(200 \mathrm{X})$.

$24 \mathrm{~h}$ and for a period of 14 days after the administration of $S$. laurifolius leaf extract. S. laurifolius leaf extract was found to be non toxic up to the dose of more than 2 $\mathrm{g} / \mathrm{kg}$ which was similar to previous reports, where it was observed that the plant did not show any signs of toxicity up to $2 \mathrm{~g} / \mathrm{kg}$ and minimum lethal dose was greater than $2 \mathrm{~g} / \mathrm{kg}$ when given orally in Albino mice and rats $[15,16]$. Based on these observations, plant $S$. laurifolius is categorized in unclassified group under Globally Harmonised System of Classification.

The clinical findings observed in repeated 28 days oral toxicity study were similar to the earlier findings of Witthawaskul et al[17] who reported that saponins gave rise to toxic manifestation in rats, symptoms included weakness, anorexia, weight loss. Saponin content of the plant could have resulted in S. laurifolius toxicity in the cattle. Saponin might have under gone reduction in rumen to get absorbed through intestine and caused rupture of various cell membranes of neurons and muscle fibers leading to release of calcium from calcium ion channels [18]. This would have resulted in increased muscle contraction, tremor, excitation observed in the large animals.

The elevated serum AST and ALT concentration and increased total protein level compared to control group is suggestive of the possible role of saponins present in gavaged extract in liver damage [19]. The increase in the concentrations of serum ALT and AST can be specifically attributed to liver damage caused by the $S$. laurifolius leaf extract, which could have caused altered membrane permeability or liver cell necrosis and cytosol leakage in to the serum [20]. Other possible causes are increased enzyme synthesis or decreased catabolism, which result in the release of intracellular enzymes into the blood stream [21].The results of present study showed that AST and ALT levels were elevated in the treated rats which indicated hepatocellular damage or injury caused by high doses of methanolic extract of $S$. laurifolius.

The altered protein concentration might be attributed to functional nephrotoxicity and hepatotoxicity, the total protein increased in high dose group compare to control group, an increase in total protein may be due

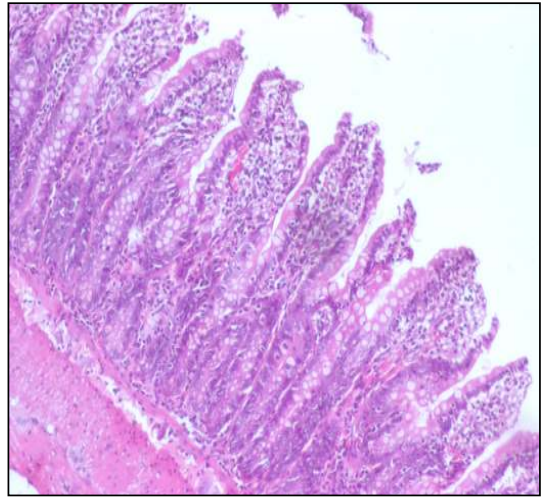

Figure-3. Histopathology image of intestine from Group IV rat showing increased goblet cell activity, destruction and shortening of the villi in repeated 28 day toxicity study by $\mathrm{H}$ and $\mathrm{E}$ stain $(100 \mathrm{X})$

to their increase in synthesis in liver [22]. also It is reported that in various liver dysfunctions, generally the protein content increases so as to maintain the protein concentration in the liver [23]. The altered level of serum total protein also noticed in rats administered with plant extract containing saponin at doses of 5, 70, and $2000 \mathrm{mg} / \mathrm{kg}$ per day a forty-day toxicity study [19]. Subacute toxicity of the saponin mixture was evaluated with the dose of $1000 \mathrm{mg} / \mathrm{kg}$ orally for 14 days [17], AST, ALT and alkaline phospatase activity was increased in saponin-received rats and it was found that the saponin mixture directly impacts the liver. Saponin was one of the important ingredients of S. laurifolius leaves, which might be responsible for the observations made in the present study.

The elevated serum creatinine and urea nitrogen in comparison to control concentration is suggestive of the possible role of saponins in causing kidney damage. Such type of kidney damage was also reported with elevation of serum creatinine and urea nitrogen concentration [24].

The functional studies in toxicology should be coupled with the appropriate histological studies, because appropriate morphological studies are useful for anatomical localization of action of toxin [23]. In the present study, the findings observed at the higher dose of $800 \mathrm{mg} / \mathrm{kg} /$ day and lethal dose of 1000 $\mathrm{mg} / \mathrm{kg} /$ day were well corroborated by histological outcomes of liver, kidney and intestine. The histopathological changes of intestine also correlated with the earlier findings of Cherian et al. [25] who had reported the toxic action of saponins in rats. It was found that saponin affects absorptive cells of the intestinal mucosa, especially those near the tips of the villi, there was severe intestinal inflammation and increased goblet cell activity.

The histopathological changes noted in the present study were similar with the effects of saponin on histopathological changes in mice. Diwan et al. [26] administered $0.5 \mathrm{ml}$ of saponin solution to six groups containing 50,100,150,250, 350 and $600 \mathrm{mg} / \mathrm{kg}$, control group received $0.5 \mathrm{ml}$ of saline solution. The histopathological changes were found to correlate with 
the increased dose of saponin. Thus saponin present in plant $S$. laurifolius might be responsible for the histopathological lesions observed in liver, kidney and intestine.

\section{Conclusion}

HPTLC fingerprint analysis can be used as a diagnostic tool for the correct identification of the plant. HPTLC revealed the phytoconstituents of $S$. laurifolius, and thus the presence or absence of chemical constituent has been found useful in the identification of medicinal and toxicological properties of the plant. The acute oral toxicity study of $S$. laurifolius methanolic leaf extract in rats, resulted in no toxicity even at the highest dose, $\mathrm{LD}_{50}$ cut off value more than $2 \mathrm{~g} / \mathrm{kg}$, and in repeated 28-day oral toxicity study, plant has toxic potential only when administered for longer duration in high concentration. It was also observed that oral administration of methanolic extract of $S$. laurifolius had adverse biochemical and histological effects with mild to moderate hepatotoxicity, severe nephrotoxicity and intestinal damage. The changes were found to correlate with the increased dose of methanolic leaf extract.

\section{Authors' contributions}

CNSK: Conducted research work. phytochemical and toxicological analysis, statistical analysis, gross and histopathological identification and drafted the manuscript. NBS: Prepared plan of work, programme of research, major role in phytochemical analysis and revised the manuscript. JSS: Helped in the programme of research, major role in histopathological slide reading, corrected article. AD: Helped in collection and identification of plant material from the Western Ghats of Karnataka. All authors read and approved the final manuscript.

\section{Acknowledgements}

The authors are thankful to the Government of Karnataka, India for funding the project: "Obscure Diseases of Cattle and Buffaloes of Karnataka: Studies on Cause and Cure". This study is the part of this project.

\section{Competing interests}

The authors declare that they have no competing interests.

\section{References}

1. Saxena, D., Pal, R., Dwivedi, A.K. and Singh S. (2004) Characterization of sapindosides in Sapindusmukorosii saponin (reethasaponin) and quantitative determination of sapindoside B. J. Sci. Indus. Res. 63(2):181-186.

2. Shiau, I.L., Shih, T.L., Wang, Y.N., Chen, H.T., Lan, H.F. and Lin, H.C. (2009) Quantification for saponin from a soapberry ( $S$. mukorossi) in cleaning products by a chromatographic and two colorimetric assays. J. Fac. Agric. Kyushu University.54(1):215-221.

3. Vaidyaratnam, P.S.V. (1996) Indian Medicinal Plants, A Compendium of 500 Species. Orient Longman,India, p. 63.

4. Pokharkar, R.D., Saraswat, R.K. andSheetal,K.R.Nagar (2010) Survey of plants having antifertility activity from Western Ghat area of Maharashtra State. J. Herbal Med.
Toxicol.4(2):71-75.

5. Mikail, H.G. (2010)Phytochemical screening, elemental analysis and acute toxicity of aqueous extract of Allium sativum L. bulbs in experimental rabbits. Indian J. Med. Res. 4(4):322-326.

6. Amit.,Bansal, P., Gupta, V., Singh, R. andChaudhary, A.K. (2010) Pharmacological potential of medicinal plant used in treatment of gout. Drug Invention Today, 2(10):433-435.

7. Attele, A.S., Wu, J.A. andYuan, C.S. (1999) Ginseng pharmacology-Multiple constituents and multiple actions. Biochem. Pharmacol. 58:1685-1693.

8. Shridhar, N.B. andNarayana, K. (2004) Toxicity studies of Sapinduslaurifolis in cross bred male calves: $23^{\text {rd }}$ Conference of Society of Toxicology,Lucknow, p. 24.

9. Wagner, H., Bladt, S. andZgainski, E.M. (1984) Plant drug analysis; A thin layer chromatography atlas. $2^{\text {nd }} e d n$, Springer-Verlag: Berlin Heidelberg, New York, p. 50-244.

10. Diener, W., Mischke, U. andKayser, D. (1995) Schedule E. The biometric evaluation of the acute toxic class method (oral). Arch Toxicol. 69:729-734.

11. Luna, L. G. (1968) Manual of histologic staining methods ofthe Armed Forces Institute of Pathology. $3^{\text {rd }}$ Ed. McGrawHill Book Company, New York, USA.

12. Steel, R.G.D. andTorrie, J.H. (1996) Principles and Procedures of Statistics. McGraw-Hill, New York, USA.

13. Kasai, R., Fujino, H., Kuzuki, T., Wong, W.H., Goto, C. andYata, N. (1986). Acyclic sesquiterpeneoligoglycosides from pericarps of Sapindusmukurossi. Phytochem. 25: 871876.

14. Vaghasiya, Y., Nair, R. andChanda, S. (2009) Antibacterial evaluation of Sapindusemarginatus leaf in in vitro conditions. Int. J. of Green Pharm. 9:165-166.

15. Kishore, D.V., Jennifer, P. and Mini, K.V. (2011) Antiulcer activity of methanolic and aqueous extracts of leaves of Sapindustrifoliatus. Int. J.Pharmaceut.Sci: Rev. and Res.6(1): 25-26.

16. Jeyabalan, S. andPalayan, M. (2009)CNS activity of the methanol extracts of Sapindusemarginatusin experimental animal models. J. Sci. Res.1(3):583-593.

17. Witthawaskul, P., Panthong, A., Kanjanapothi, D., Taesothikul, T. andLertprasertsuke. N. (2003)Acute and subacute toxicities of the saponin mixture isolated from Scheffleraleucantha leaves.J Ethnopharma. 89(1):115-121.

18. Berridge, M.J. and Taylor, C.W. (1988) Inositol Trisphosphate and Calcium Signaling. Cold Spring Harb.Symp. Quant. Biol. 53: 927-933.

19. Lakmichi, H., Bakhtaoui, F.Z., Gadhi, C.A., Ezoubeiri, A., Jahiri. AndElmansouri, A. (2011) Toxicity profile of the aqueous ethanol root extract of CorrigiolatelephiifoliaPourr. In rodents. Evidence-Based Complement Altern. Med.11:1-10.

20. Ozer, j., Ratner, M., Shaw, M., Bailey, W. andSchomaker, S. (2008) The current state of serum biomarkers of hepatotoxicity. Toxicology, 245;194-205.

21. Rouiller, C. (1964) The liver morphology, Biochemistry and pathology. Academic Press, New York, p. 335.

22. Banaee, M., Mirvagefei, A.R., Rafei, G.R. andMajazi, A.B. (2008) Effect of sub-lethal Diazinon Concentration on BloodcPlasma Biochemistry. Int. J. Environ. Res. 2:189-198.

23. Sagar, K. andVidyasagar, G.M. (2010) Evaluation of acute toxicities of leaf extract of Caesalpiniabonducella (L.) Flem. Int. J.Pharma.Biosci. 6:1-15.

24. Wisloff, H., Uhlig, S., Scheie, E., Loader, J., Wilkins, A. and Yen, A.F. (2008) Toxicity testing of saponin containing Yucca SchidigeraRoetzl. Juice in relation to hepato and nephrotoxicity of NartheciumOssifragum (L.) huds. Toxicon. 51(1):140-150.

25. Cherian, K.M., Gandhi, V.M. andMulky, M. (1996) Toxicological evaluation of Mowrah (Madhucalatifolia) seed material. Indian J. Exp. Biol. 34:61-65.

26. Diwan, F.H., Abdel-Hassan, I.A. and Mohammed, S.T. (2000) Effect of saponin on mortality and histopathological changes in mice. East. Med. Health J.6(3):345-351. **** 